\title{
PHASE STABILITY OF MONOATOMIC ALCOHOL-GASOLINE MIXTURES FOR DIFFERENT COMPOSITIONS AND HYDRODYNAMIC CONDITIONS
}

\author{
Valerian Cerempei \\ Institute of Agricultural Technics Mecagro, 7, M. Costin str., Chisinau, MD 2068 R. Moldova \\ e-mail:icmea_mecagro@yahoo.com
}

\begin{abstract}
The article investigates phase stability for the mixtures of monoatomic alcohols (ethanol, butanol) with gasoline in the presence of water. There have been determined the optimal storage conditions of mixtures depending on their composition and mixing conditions. The positive influence of butanol on the phase stability of ethanolgasoline mixtures was detected.
\end{abstract}

Keywords: butanol, ethanol, gasoline, mixtures, phase stability.

\section{Introduction}

In the last 30-40 years, because of a rapid growth in prices for crude oil, the interest for alternative sources of energy including biomass, which the world economy and the Republic of Moldova possess in a sufficient extent, has increased in the world economy [1]. As a result, in order to supply spark ignition engines (SIE), there are increasingly used the mixtures of gasoline with monoatomic alcohols obtained from biomass. During the investigation [2-5] there have been studied physical-chemical and operational properties reflecting the combustion capacity of these mixtures.

Simultaneously, it is well known that monoatomic alcohols, especially methanol and ethanol $\mathrm{C}_{2} \mathrm{H}_{5} \mathrm{OH}$ interact with water $\mathrm{H}_{2} \mathrm{O}$ thus diminishing phase stability of alcohol-gasoline mixtures. But the existing literature lacks specific information concerning phase stability of the mentioned mixtures.

Therefore, the purpose of our research is to determine the composition of monatomic alcohol - gasoline mixtures and hydrodynamic conditions, which ensure high values of the phase stability.

\section{Methodology of experimental researches}

For the researches there have been used: ethanol $\mathrm{C}_{2} \mathrm{H}_{5} \mathrm{OH}$ (volume fraction of absolute alcohol - 95.7-98\% vol.), butanol $\mathrm{C}_{4} \mathrm{H}_{9} \mathrm{OH}$ (absolute alcohol - 99.9\% vol.) and regular gasoline -80 with low octane ( $\left.\mathrm{RON} \geq 80\right)$.

There have been studied separately the components forming the mixtures (gasoline 100\%, butanol 100\%, ethanol 100\%) and their mixtures: butanol - gasoline (B10, B20, B30, B50, which contain respectively 10, 20, 30, 50\% vol. of butanol), ethanol - gasoline (E10, E20, E30, E40, E50, E60, E85, which contain respectively 10, 20, 30, 40, 50, $60,85 \%$ vol. of ethanol), ethanol - butanol - gasoline (E16 - B16, containing 16\% vol. of ethanol, $16 \%$ vol. of butanol, $68 \%$ vol. of gasoline).

To research the phase stability, there were prepared fuel samples with a volume of $100 \mathrm{ml}$ each one. To these samples there were added $5 \mathrm{ml}$ of water with and without agitation. Shaking was performed by electromagnetic stirring having a constant intensity for all samples and duration of $0.5,2.0,5.0,10.0$, and 20.0 minutes. The studied mixtures had an average temperature of $+20^{\circ} \mathrm{C}$.

Phase stability was assessed visually according to liquid state (cloudy, clear), duration of liquid clearing, the absence or existence of sediment and its volume.

\section{Results and discussions}

According to the obtained results (tab. 1, fig. 1), adding water without agitation $\left(\tau_{\text {agit }}=0\right)$ in any pure fuel has as a consequence practically the instant clearing of these mixtures and the volume fraction of sediments in these fuels is as follows: gasoline $-5 \mathrm{ml}$, butanol $-4 \mathrm{ml}$, ethanol $-0 \mathrm{ml}$.

The agitation of gasoline-water and ethanol-water mixtures does not change the liquid state. After the agitation, the entire quantity of added water $(5 \mathrm{ml})$ settles as sediment in the gasoline, which becomes instantaneously clear. Ethanol also becomes clear in similar conditions, dissolving all the quantity $(5 \mathrm{ml})$ of added water.

Butanol, with kinematic viscosity $\left(3.64 \mathrm{~mm}^{2} / \mathrm{s}\right) 2,4$ times higher compared with ethanol and 6.4 times higher compared to gasoline, with the addition of $5 \mathrm{ml}$ of water, dissolves only $1 \mathrm{ml}$ without agitation and the remaining $4 \mathrm{ml}$ deposit as sediment. The agitation stimulates the dispersion of water drops dissolving them in butanol $\left(\tau_{1}=0 \mathrm{~h}, \mathrm{~V}_{\mathrm{s}}=0\right.$ $\mathrm{ml})$.

The behavior of gasoline, butanol and ethanol when adding water corresponds to their composition and molecules structure. Because of hydrogen links formation between alcohol and water molecules, the alcohols dissolve well in water. The solubility decrease in water of superior alcohols is a consequence of the increasing influence of 
hydrocarbon radical. Gasoline contains $\mathrm{C}_{\mathrm{n}} \mathrm{H}_{\mathrm{m}}$ hydrocarbons of over 200 types [6], having an average molecular weight within $110-120 \mathrm{~kg} / \mathrm{kmol}$ and the value of dielectric permeability $\varepsilon 1,9-2,1$ [7]. Ethanol and butanol are monatomic saturated alcohols $\mathrm{C}_{\mathrm{n}} \mathrm{H}_{2 \mathrm{n}+1} \mathrm{OH}$. Ethanol $\mathrm{C}_{2} \mathrm{H}_{5} \mathrm{OH}$ has a molecular weight of $46 \mathrm{~kg} / \mathrm{kmol}$ and dielectric permeability of 32 , and butanol $\mathrm{C}_{4} \mathrm{H}_{9} \mathrm{OH}-74 \mathrm{~kg} / \mathrm{kmol}$ and 23 respectively (for comparison, water $\mathrm{H}_{2} \mathrm{O}$ molecular weight is $18 \mathrm{~kg} / \mathrm{kmol}$, and the dielectric permeability - 81).

Table 1

\section{The influence of mixing conditions of different fuels with water on the duration of liquid clearing $\tau_{1}$ and volume of sediment $V_{s}$}

\begin{tabular}{|c|c|c|c|c|c|c|c|c|c|c|c|c|}
\hline \multirow{3}{*}{ Fuel } & \multicolumn{12}{|c|}{ Duration of agitation, min } \\
\hline & \multicolumn{2}{|c|}{0} & \multicolumn{2}{|c|}{0,5} & \multicolumn{2}{|c|}{2} & \multicolumn{2}{|c|}{5} & \multicolumn{2}{|c|}{10} & \multicolumn{2}{|c|}{20} \\
\hline & $\tau_{1}, \mathrm{~h}$ & $\mathrm{~V}_{\mathrm{s}}, \mathrm{ml}$ & $\tau_{1}, \mathrm{~h}$ & $\begin{array}{l}\mathrm{V}_{\mathrm{s}}, \\
\mathrm{ml}\end{array}$ & $\tau_{1}, \mathrm{~h}$ & $\begin{array}{l}\mathrm{V}_{\mathrm{s}}, \\
\mathrm{ml}\end{array}$ & $\tau_{1}, \mathrm{~h}$ & $\mathrm{~V}_{\mathrm{s}}, \mathrm{ml}$ & $\tau_{1}, \mathrm{~h}$ & $\begin{array}{l}\mathrm{V}_{\mathrm{s}} \\
\mathrm{ml}\end{array}$ & $\tau_{1}, \mathrm{~h}$ & $\mathrm{~V}_{\mathrm{s}}, \mathrm{ml}$ \\
\hline 1.Gasoline $(100 \%)$ & 0 & 5 & 0 & 5 & 0 & 5 & 0 & 5 & 0 & 5 & 0 & 5 \\
\hline 2. Butanol (100\%) & 0 & 4 & 0 & 0 & 0 & 0 & 0 & 0 & 0 & 0 & 0 & 0 \\
\hline 3. Ethanol $(100 \%)$ & 0 & 0 & 0 & 0 & 0 & 0 & 0 & 0 & 0 & 0 & 0 & 0 \\
\hline $\begin{array}{l}\text { 4.Mixtures: } \\
\text { 4.1. B10 }\end{array}$ & 0 & 5 & 0,25 & 5 & 17,1 & 5 & 20,1 & 5 & 23,6 & 5 & 24,5 & 5 \\
\hline 4.2. $\mathrm{B} 20$ & 0 & 5 & 1,2 & 5 & 17,4 & 5 & 21 & 4,5 & 23,7 & 5 & 24,8 & 4,7 \\
\hline 4.3. B30 & 0 & 5 & 2,7 & 5 & 18,5 & 5 & 21,3 & 4,3 & 24,1 & 4,8 & 25,1 & 4 \\
\hline 4.4. B50 & 0 & 5 & 0,5 & 2,5 & 1,5 & 2 & 15,8 & 2 & 17,5 & 2 & 17,8 & 1 \\
\hline 4.5. E10 & 0 & 5,5 & 0,4 & 13 & 0,45 & 12 & 0,45 & 13 & 0,43 & 13 & 0,38 & 12 \\
\hline 4.6. E20 (FEA) & 0 & 8 & 0,37 & 22 & 0,42 & 22 & 0,38 & 22 & 0,32 & 22 & 0,33 & 21 \\
\hline 4.7. E20 (alim) & 0,8 & 15 & 4,55 & 24 & 3,43 & 24 & 3,2 & 24 & 3,02 & 24 & 2,45 & 24 \\
\hline 4.8. E30 & 0 & 11 & 0,15 & 35 & 0,33 & 35 & 0,33 & 36 & 0,32 & 36 & 0,35 & 34 \\
\hline 4.9. E40 & 0 & 12 & 0,024 & 50 & 0,011 & 44 & 0,013 & 50 & 0,013 & 50 & 0,018 & 50 \\
\hline 4.10.E50 & 0,17 & 67 & 0,029 & 67 & 0,015 & 72 & 0,024 & 72 & 0,029 & 73 & 0,019 & 67 \\
\hline 4.11. E60 & 0,033 & 69 & 0,015 & 96 & 0,13 & 95 & 0,17 & 94 & 0,17 & 97 & 0 & 0 \\
\hline 4.12. E85 & 0 & 0 & 0 & 0 & 0 & 0 & 0 & 0 & 0 & 0 & 0 & 0 \\
\hline $\begin{array}{c}\text { 4.13. E16 B16 } \\
\text { (FEA) }\end{array}$ & 0 & 5 & 1,88 & 4 & 4,5 & 5 & 4,8 & 5 & 5 & 5 & 5,3 & 5 \\
\hline $\begin{array}{l}\text { 4.14. E16B16 } \\
\text { (alim) }\end{array}$ & 0 & 9 & 1,21 & 6,5 & 3,6 & 7 & 4,13 & 7 & 4,2 & 7 & 4,08 & 7 \\
\hline
\end{tabular}

Dielectric permeability of water and alcohols is influenced by strongly polar group $\mathrm{OH}^{-}$, which has the greatest influence in water $(\varepsilon=81)$, then decreases its influence - in ethanol $(\varepsilon=32)$ and butanol $(\varepsilon=23)$. The values of listed properties explain practically absolute indissolubility of water $\mathrm{H}_{2} \mathrm{O}$ in gasoline, limited water solubility in butanol and unlimited in ethanol.

In most cases, adding water in monoatomic alcohol-gasoline fuel mixtures without agitation has identical consequences - instant clearing (Tab. 1). Only in E50 and E60 mixtures the clearing took 0.17 hours (10 minutes) and 0.03 hours $(2$ minutes). The volume of sediment in the mixtures butanol-gasoline B10 ... B50, ethanol - butanol gasoline E16B16 is equal to the volume of added water $(5 \mathrm{ml})$. In the mixtures of ethanol-gasoline, sediment volume increased from $5.5 \mathrm{ml}$ (E 10) to $69 \mathrm{ml}$ (E60), decreasing to $0 \mathrm{ml}$ in the mixture E85. 
We can assume that in the mixtures E10 ... E40, ethanol increasingly deposits as sediment together with water as its concentration in the mixtures increases. In the mixtures E50 and E60, the sediment includes not only water, ethanol, but also perhaps certain hydrocarbons from gasoline. In the mixture E85 (sediment volume of which is $0 \mathrm{ml}$ ), water and gasoline are assimilated (diluted) by ethanol.

The agitation of monoatomic alcohol-gasoline-water mixtures is the cause of water droplets dispersion in monoatomic alcohol-gasoline solutions, thus they becoming cloudy. In all the mixtures with butanol, an increase in the duration of agitation would first of all lead to the increase of the clearing duration $\tau_{1}$ (Fig. 1). Shaking for 0.5 minutes butanol-gasoline-water mixtures B10 ... B50 allows to keep them cloudy, and the clearing duration being for B10 $\tau_{1}=0,25$ $\mathrm{h}$ (sediment volume $-5 \mathrm{ml}), \mathrm{B} 20-\tau_{1}=1,2 \mathrm{~h}\left(\mathrm{~V}_{\mathrm{s}}=5 \mathrm{ml}\right), \mathrm{B} 30-\tau_{1}=2,7 \mathrm{~h}\left(\mathrm{~V}_{\mathrm{s}}=5 \mathrm{ml}\right), \mathrm{B} 50-\tau_{1}=0,5 \mathrm{~h}\left(\mathrm{~V}_{\mathrm{s}}=2,5 \mathrm{ml}\right)$.

When increasing the duration of agitation of butanol mixtures with up to 20 minutes leads to a stabilization of clearing conditions (Fig. 1), maintaining $\tau_{1}$ values at 24.5-25.1 h for B10...B30 and $17.8 \mathrm{~h}$ for B50. The volume of sediment in these conditions maintains in the mixture B $10(5 \mathrm{ml})$ and decreases in the mixtures B20 ... B50. Its decreasing degree increases while butanol concentration increases: $V_{s}=4,7 \mathrm{ml}$ in $B 20, V_{s}=4 \mathrm{ml}$ in $B 30, V_{s}=1 \mathrm{ml}$ in $\mathrm{B} 50$ ( $\mathrm{tab}$ 1.). The decrease of sediment volume can be explained by the dissolution of a part of water in butanol.

The agitation of ethanol-gasoline-water mixtures during 0.5 minutes increases the clearing period $\tau_{1}$ compared with stationary conditions up to $0.4 \mathrm{~h}$ (E10), the following values being in decrease: $\tau_{1}=0,37 \mathrm{~h}(\mathrm{E} 20), \tau_{1}=0,15 \mathrm{~h}(\mathrm{E} 30)$; $\tau_{1}=0,024 \mathrm{~h}(\mathrm{E} 40) ; \tau_{1}=0,029 \mathrm{~h}(\mathrm{E} 50), \tau_{1}=0,015 \mathrm{~h}(\mathrm{E} 60), \tau_{1}=0 \mathrm{~h}(\mathrm{E} 85)$.

The decrease of clearing period occurs, probably, due to the increase of ethanol fraction and consequently of its influence. All this also explains the increase in sediment volume: $\mathrm{V}_{\mathrm{s}}=13 \mathrm{ml}(\mathrm{E} 10), \mathrm{V}_{\mathrm{s}}=22 \mathrm{ml}(\mathrm{E} 20), \mathrm{V}_{\mathrm{s}}=35 \mathrm{ml}$ (E30), $\mathrm{V}_{\mathrm{s}}=50 \mathrm{ml}(\mathrm{E} 40), \mathrm{V}_{\mathrm{s}}=67 \mathrm{ml}(\mathrm{E} 50), \mathrm{V}_{\mathrm{s}}=96 \mathrm{ml}(\mathrm{E} 60)$. In the mixture E85, as already mentioned, the influence of ethanol prevails dissolving momentaneously the gasoline and water.

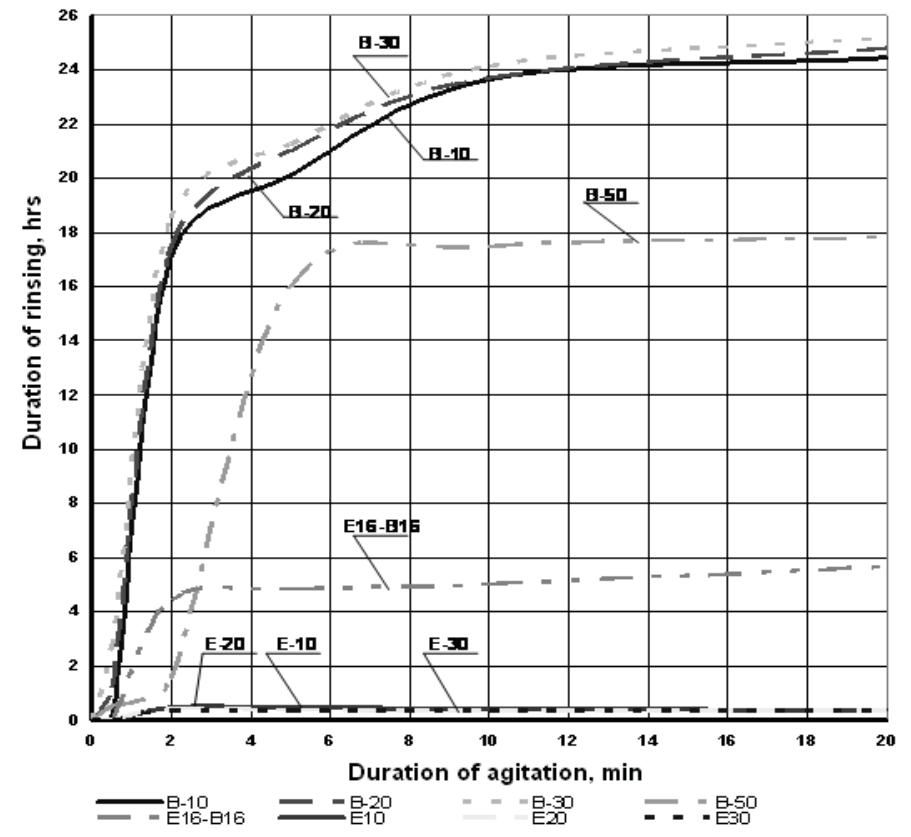

Fig. 1. The influence of the duration of agitation on the duration of clearing of monoatomic alcohol-gasoline-water mixtures

Increasing the duration of agitation up to 20 minutes does not change anything in the behavior of mixtures E10 ... E40, the duration of clearing and volume of sediment varying in narrow limits. The mixtures E50 and E60 present a variant of transition from the mixtures E10...E40 to the mixtures E85...E100. Increasing the duration of agitation up to 20 minutes we reduce sediment volume in the mixture E50 from 73 to $67 \mathrm{ml}$, and in the mixture E60 - from 97 to $0 \mathrm{ml}$, the period of clearing decreasing from 0.17 to $0 \mathrm{~h}$.

Our researches proved the dependence of phase stability in mixtures on ethanol composition (Table 1). Using ethero-aldehyde fraction - EAF (98\% vol. of absolute alcohol) in the preparation of mixture E20 allows a faster fuel clearing when adding water than in the case when purified alimentary alcohol (95,7\% vol. a.a.) is used.

At the same time when adding water the volume of sediment in the mixtures E20 and E16B16 which are prepared with alimentary alcohol is mostly about $2 \mathrm{ml}$ higher than in the mixtures prepared on the basis of etheroaldehyde fraction. The difference in volumes of sediments is probably linked to differences in the composition of ethylic alcohol, including water fraction. 
It should be mentioned that ethero-aldehyde fractions contain relatively large amounts of aldehydes, esters, fusel oil, volatile acids in comparison to alimentary alcohol. This fact influences the properties of alcohol and mentioned mixtures.

Therefore, the accomplished researches prove the dependence of phase stability in biofuels on their composition, agitation regimes, and allow determining the optimal conditions of storage and use of biofuels.

\section{Conclusions}

1. Studied pure fuels (gasoline, butanol, ethanol) and their mixtures butanol-gasoline B10 ... B50, ethanol-butanolgasoline E16B16, have high properties of phase stability. Adding water into gasoline, butanol and their mixtures results in its sedimentation in an equal or less volume than the added volume. The water added in ethanol is completely dissolved.

2. The agitation of butanol-gasoline mixtures increases their clearing period up to 24.5 ... 25.1 hours and reduces the volume of sediment, dissolving a part of the added water in butanol. When increasing butanol fraction in the mixture, water volume increases too, and this is dissolved in butanol.

3. In the triple mixture of ethanol-butanol-gasoline E16B16, water addition has as consequence only its sedimentation, and the remaining ethanol in the fuel mixture obtains high phase stability due to butanol.

4. Butanol, butanol-gasoline mixture $\mathrm{B} 10 \ldots \mathrm{B} 30$, and ethanol-butanol-gasoline mixture E16B16 require practically identical conditions for the storage process as in the case of gasoline. In this case, the water that gets into fuel (for example, condensed), deposits as sediment for up to 25 hours after which the mixture can be used.

5. Addition of water to ethanol-gasoline mixture E10 ... E30 is the cause of not only water sedimentation but also of ethanol, which can be removed in this way from the fuel mixture. In the mixtures E40 ... E60, together with water and ethanol, certain gasoline fractions decant.

6. Intensive agitation for a relatively long duration (20 minutes) of E60 mixtures allow to obtain a transparent and homogeneous liquid without sediment. The same state can be also achieved in the case of the mixture E85, when adding water with and without agitation due to gasoline and water dissolution in ethanol.

7. Addition of water changes ethanol properties and ethanol-gasoline mixtures while maintaining phase stability in ethanol of the mixtures E60 (with intensive agitation), E85 or excluding it in the mixtures E10 ... E50, E60 (without agitation). Therefore, the mentioned fuels submit more exigent requirements referred to their storage conditions regarding the minimization of water penetration.

8. Faster clearing of ethanol-gasoline mixtures $\left(\tau_{1} \leq 0,45 \mathrm{~h}\right)$ compared with butanol-gasoline mixtures $\left(\tau_{1} \leq 25 \mathrm{~h}\right)$ can be explained by ethanol viscosity which is 2.4 times smaller than that of butanol. The obtained results can serve as a basis for establishing the duration of clearing of fuel mixtures in practical conditions.

9. The obtained results allow determining the most efficient agitation regimes of the mixtures ethanol-gasoline and butanol-gasoline with water surplus directly in the composition of supply system of internal combustion engines to achieve optimal composition of combustion air-fuel mixtures.

10. The use of ethylic alcohol of different compositions (purified alimentary alcohol, ethero-aldehyde fraction) changes slightly phase stability, which practically does not affect their conditions of storage and use.

\section{References}

[1]. "World Consumption of Primary Energy Type and Selected Country Groups, 1980-2004" (XLS). Energy Information Administration, U.S. Department of Energy. July 31 2006. http://www.eia.doe.gov/pub/international/ iealf/table 18.xls. Retrieved o 2007-01-20.

[2]. Смаль Ф. В., Арсенов Е.Е. Перспективные топлива для автомобилей. М.: Транспорт, 1979-151 с.

[3]. Manea Gh., Georgescu M. Metanolul - combustibil neconvențional. Bucureşti: Tehnică, $1992-84$ p.

[4]. Gheorghişor M. Carburanți, lubrifianți şi materiale auto speciale. Bucureşti: Paralela, $2003-324$ p.

[5]. Energie din biomasă: tehnologii şi mijloace tehnice/ Ion Hăbăşescu, Valerian Cerempei, Vasile Deleu şi alț. Chişinău: Bons Offices, 2009 - 368 p.

[6]. Лышко Г.П. и др. Топливо, смазочные материалы и технические жидкости. Кишинев: ГАУМ, 1997 $486 \mathrm{c}$.

[7]. Справочник химика, т. 6. Л: Химия, $1967-1012$ с. 